\title{
AN ANALYSIS OF PERCEPTIONS AND AWARENESS OF RISK ASSOCIATED WITH ENERGY PIPELINES IN SOUTH AFRICA
}

\author{
TATENDA MBARA* \\ HUGO VAN DEN BERG** \\ *tmbara@uj.ac.za \\ **hugov@uj.ac.za \\ Department of Transport and Supply Chain Management \\ University of Johannesburg, South Africa
}

\begin{abstract}
Worldwide, there has been a rapid growth in the use of pipelines to transport energy products. Due to the strategic nature of energy products that are transported by pipelines, the importance of risk awareness, assessment and management cannot be overemphasised. With the risk of pipeline disruptions increasing globally, energy pipeline organisations are compelled to incorporate measures that should help to identify and address areas that can lead to energy pipeline disruptions. The incorporation of such measures for any organisation is premised on an understanding and appreciation of the risks involved. Given the strategic importance of energy pipelines, the main purpose of this paper is to establish whether the South African energy pipeline sector and the public at large appreciate the risks associated with energy pipelines. Thus, the paper seeks to ascertain awareness of the risks associated with the energy pipeline's physical environment, not only from the energy pipeline operators, but also from communities who are exposed to such risks. Data for the study was collected from energy pipeline operators and from a selected residential area in Johannesburg using both structured and unstructured questionnaires. The findings show that the corporate energy sector in South Africa is aware of risks associated with energy pipeline supply chains while the general public's awareness is very low.
\end{abstract}

\section{INTRODUCTION}

While pipelines are capable of transporting a variety of products, it is in the distribution of energy products (liquid fuel and gas) where they have gained prominence. Pipeline technology has been in existence for many years and the first commercial pipeline to transport oil was built in 1859 following the successful extraction of oil in Titusville, Pennsylvania in the United States of America (Tarbell, 1904). Since then, there has been a rapid worldwide growth in the use of pipelines to transport energy products, particularly in the last few decades, as evidenced in a subsequent section on literature review. 
Pipelines offer significant benefits to modern supply chains through their economic benefits, reliability, higher levels of safety and convenience, as products can be delivered directly to consumers. Notwithstanding the initial high capital outlay costs, operating costs are relatively small and they are extremely efficient due to substantial volumes that can be distributed resulting in greater economies of scale (Liu, 2003:9; Pienaar, 2010:235). In addition, products transported by pipelines do not require packaging and the land required for laying pipeline infrastructure is relatively small in comparison with other transportation modes. Some other economic benefits include minimal loss and damage as the movement of the product is covered and protected, and lower energy usage when compared to other modes in moving an equivalent mass of product (Bardi, Coyle \& Novack, 2006:149).

While energy products are highly sought after worldwide, their shortage has often caused price escalations resulting in economic instability. Due to the strategic nature of energy products that are transported by pipelines, the importance of risk awareness, assessment and management becomes imperative. With the risk of pipeline disruptions increasing globally, energy pipeline organisations are forced to incorporate measures that should help to identify and address areas that can lead to energy pipeline disruptions. Pickford (2001:141) points out that the minimisation of risk to resources is indispensable for success in pipeline operations.

Given the strategic importance of energy pipelines and the potential disruptions that may occur, the main purpose of this paper is to assess the awareness of the South African energy pipeline sector of the risks associated with energy pipelines. The energy pipeline sector in this paper is defined as the corporate pipeline operators and the public as represented by residents residing in an environment that pipelines pass through.

Factors associated with security create uncertainty in the markets. Such uncertainty is fundamental to risk and will possibly draw attention to existing or new risks. The paper endeavours to ascertain how the risks associated with energy pipelines are perceived, not only by the pipeline operators, but the general public as well. Thus, the focus of the paper is not on risk assessment and management measures per se, but on primarily ascertaining whether such risks are appreciated by both the corporate and public sectors in South Africa.

The importance of risk awareness in the energy pipeline sector cannot be overemphasised. According to Mileti (1993:143), people respond to a risk in ways that are consistent with their perception of that risk and it is their perception that influences behaviour or action. Clearly an appreciation of potential risks and an understanding that a dangerous incident can happen at any time is a necessary requirement for preparedness. Janis and Mann (1977) argue that 'adaptive actions are motivated by awareness of the hazard, knowledge of how it can affect the community and feelings of personal vulnerability to the potential 
consequences'. Thus, a study on risk awareness in the energy pipeline sector is important as it demonstrates peoples' preparedness for any hazardous pipeline event.

\section{RESEARCH STRATEGY}

A comprehensive literature review was conducted in order to gain an understanding of developments in the pipeline industry. The literature review gathered information on the state of the pipeline sector worldwide, and risks associated with energy pipeline supply chains. In the ensuing literature search, it became clear that there is a paucity of literature on the subject relating to South Africa.

In order to obtain information on awareness of risks associated with energy pipelines, a structured questionnaire was administered to the three main companies that operate energy pipelines (gas and petroleum) in the country. In addition to corporate risk awareness, a household survey was undertaken in a selected residential area in Johannesburg in order to ascertain the general public awareness of risks pertaining to gas pipelines. The residential area was selected due to its proximity to the authors' work place as well as the recommendation given by the company supplying gas to the area. A total of 125 households (target sample), constituting approximately $40 \%$ of a demarcated area, were interviewed. The survey was conducted randomly and covered all the streets in the area. The selected residential area has a network of gas pipelines, with some households connected to the gas supply. Interviewees included both households that are connected to gas as well as those not connected, as the latter group would also be affected in the event of a pipeline disaster occurring.

Information was also sought from those organisations associated with the physical environment surrounding the energy pipeline supply chain in South Africa and these included: a registered Environmental Risk Assessor who had previously worked with the energy pipeline organisations in South Africa, Department of Environmental Affairs, which is responsible and mandated to ensure that environmental legislation and regulations are complied with; and a senior Environmental Consultant who previously used to undertake Environmental Impact Assessments (EIA) for the construction of a New Multi-Product Pipeline (NMPP).

\section{LITERATURE REVIEW}

The demand for energy products that are distributed through pipelines has increased markedly in the last few decades. Pipelines are highly reliable because operations are largely automated, uninterrupted and not easily affected by weather (Liu, 2003:15; Bardi, et al., 2006:199-200; Pienaar, 2010:237) and their ability to function throughout the year 
enables them to satisfy demand continuously, unlike other forms of transport. Products distributed by pipelines are less prone to theft in comparison with other modes of transport where the risk is high. Thus, the ability of pipelines to deliver products without interruption provides significant economic benefits to business and community.

However, the importance of pipelines is hardly recognised due to the nature of the transportation mode, as a sizable proportion of pipelines is buried underground and therefore seemingly invisible.

As pipelines are mostly buried underneath the ground, they are likely to be perceived positively in regard to environmental problems pertaining to pollution, visual intrusion and accidents. Unlike other modes of transport, they do not cause congestion. However, pipeline disruptions can result in loss of life, injury and damage to property and/or the environment.

Globally, there are 124 countries with approximately 1.9 million km of energy pipelines that transport a variety of products which include gas, oil, liquid petroleum gas and refined products (The World Factbook, 2008). Table 1 shows the length of pipeline network of selected countries (including South Africa) and the products carried.

Table 1: Pipelines lengths $(\mathrm{km})$ of selected countries

Source: Adapted from The World Factbook, 2008

\begin{tabular}{|r|c|r|r|r|r|}
\hline Rank & Country & Gas & Liquid petroleum/gas & \multicolumn{1}{l|}{ Oil } & Total \\
\hline 1 & USA & 548665 & 0 & 244620 & 793285 \\
\hline 2 & Russia & 158767 & 127 & 74285 & 233179 \\
\hline 3 & Canada & 0 & 74980 & 23564 & 98544 \\
\hline 4 & Mexico & 22705 & 1875 & 8668 & 33243 \\
\hline 5 & Australia & 27105 & 41 & 5939 & 33085 \\
\hline 46 & South Africa & 908 & 0 & 980 & 1888 \\
\hline 124 & Lichtenstein & 20 & 0 & 0 & 20 \\
\hline
\end{tabular}

The USA has the most extensive pipeline network in the world. Pipelines transport about two-thirds of the petroleum products where they deliver 14 billion barrels of petroleum per year and account for more than $17 \%$ of the freight moved nationally, but at less than $2 \%$ of the national freight cost (Trench, 2001:2).

In Europe, there has been an unprecedented growth in energy pipelines from $12800 \mathrm{~km}$ carrying 310 million cubic metres in 1971 to 250 crude oil and products pipelines which formed a network of over $30000 \mathrm{~km}$ transporting 672 million cubic metres of oil products by 2000 (Lyons, 2002:2). 
While the operations of energy pipelines are relatively safe, there is always a risk that disruptions may occur. The potential for significant disruption is ever present as the contents of energy pipelines are often highly combustible. They are also susceptible to natural disasters such as earthquakes, floods and accidental damage. Thus, the result of any risk occurrence can lead to losses and adverse impacts on energy supply chains.

Borge (2001:3) succinctly defines risk as 'being exposed to the possibility of a bad outcome'. According to Ritter, Barrett and Wilson (2007:85), the word 'risk' suggests that there is no certainty that a type of occurrence can or will not take place and that this particular occurrence can have severe implications for the pipeline and the pipeline supply chain if it does occur. Rosa (2003: 56) also links risk to uncertainty and defined risk as 'a situation or an event where something of human value (including humans themselves) is at stake and where the outcome is uncertain'.

Bredell (2004:70) argues that wherever there is uncertainty in a supply chain, risk lurks, and that integrated supply chain management can assist in the protection and enhancement of shareholder value. Vertzberger (1998:18) goes further to suggest that risks to energy pipelines can be broken down into three categories, namely, real risk, acceptable risk and perceived risk. The latter risk, he defined as the response of different individuals and groups facing the same type and level of risk which may vary because of dissimilar perceptions. Therefore, risk may mean different things to different people.

Notwithstanding the fact that risk may be interpreted or envisaged differently by different people, the crucial question to ask is whether people are aware of possible risks in the energy pipeline environment. According to the Interstate Natural Gas Association of America (INGAA) 2011, public awareness and understanding is vital to the continued safe operations of pipelines and this includes both the operator and the public. INGAA (2011) further pointed out the importance of public awareness especially for people who live and work near pipelines in regard to how to 'recognise, respond and report abnormal conditions or questionable activities near pipelines'. Hazard recognition can be difficult. For instance, some residents initially thought the 2010 San Bruno pipeline explosion that occurred in California causing six deaths and injuring and displacing several people from their homes, was an earthquake or a crash of a large jetliner from a nearby airport (The Associated Press, 2010).

It is therefore imperative for pipeline operators and the public to be aware of risks associated with this mode of transport. Pipeline organisations are compelled to incorporate measures that would assist in identifying and addressing the risks associated with pipeline operations. Such disruptions range from minor leaks to major disruptions resulting from sabotage. Thus, the management of pipeline risks must be an integral part of any pipeline operation. Vertzberger (1998:19) suggests that the risks associated with pipelines symbolise a 
complicated interface surrounded by a specific group of actions and outcome probabilities in a specific pipeline area.

Pritchard (2001:1) argues that if risk has to be kept under control, it must be classified and goes on to categorise risks into four groups, namely:

1. High likelihood of a risk occurring, with a high impact on the business and the environment

2. High likelihood of a risk occurring, with a low impact on the business and the environment

3. Low likelihood of risk occurring, with a high impact on the business and environment

4. Low likelihood of a risk occurring, with a low impact on the business and the environment

Globally, there is evidence of numerous pipeline supply chain disruptions and a selection of a few of these disruptions that occurred within the last decade follow:

- Leakage on the Trans-Alaskan pipeline in early January 2011 resulting in a $1 \%$ rise in oil prices (Anchorage/New York, 2011)

- Sabotage of an oil pipeline in Iraq in August 2003 (Elliott, 2004)

- In Columbia, since 2001, leftists rebels have blown so many holes in a 480-mile pipeline that has become known as 'the flute' (Luft \& Korin, 2004)

- Saboteurs blowing up a pipeline carrying crude oil from Iraq's northern oil fields to the main Al-Daura refinery in Baghdad (Salopek, 2003)

- Explosion of a gasoline pipeline in December 2006 in Nigeria in the district of Abule Egba killing 260 civilians - it was suspected that the pipeline was ruptured by local bandits who had been tapping the gasoline pipeline for some time (Houreld, 2006)

- The explosion on 19 December 2010 of an oil pipeline at a Petroleos Mexicanos (Pemex) pumping station in San Martín Texmelucan de Labastida in central Mexico killing at least 27 people and injuring more than 50 (www.enotes.com/topic/List_of_pipeline_ accidents)

- San Bruno pipeline explosion in California which caused six deaths and injured several people, and displacing the latter from their homes (The Associated Press, 2010)

- Accidental leakage of an Egoli gas pipeline resulting in an explosion and evacuation of 'hundreds of people' on 1 September 2010 in South Africa (Gifford, 2010)

From the foregoing, it can be concluded that pipeline disruptions are a common occurrence. There are a number of factors that can cause pipeline disruptions and these include leakages which could be either accidental or as a result of an ageing pipeline, accidental damage and sabotage. Clearly, it is important that organisations that operate energy supply chain pipelines should be conscious of the likely occurrence of disruptions. Muhlbauer (2004:14) emphasises the point and argues that risk assessment and management must be a fundamental part of pipelines and 'not just an exercise whenever the need arises'. With the risk of pipeline disruptions increasing globally, energy pipeline organisations are 
compelled to incorporate measures to identify and address challenges that can lead to energy pipeline disruptions. The primary focus of these measures must be the safeguarding of the energy infrastructure and the protection of the natural environment through which the pipelines pass.

\section{RISK PERCEPTIONS OF ENERGY PIPELINES}

This section focuses on the findings of the study undertaken. The first part covers the risk awareness of South African pipeline operators while the second focuses on risk awareness of energy pipelines by the general public.

\section{Pipeline operators' perceptions and awareness}

\section{Overview}

South Africa has an extensive network of pipelines that transport crude oil, refined products and gas. There are $908 \mathrm{~km}$ of gas pipelines and $980 \mathrm{~km}$ of oil pipelines making a total network of $1880 \mathrm{~km}$ of pipelines (The World Factbook 2008) and the network continues to expand. Three companies, namely, Transnet, Egoli gas and Sasol, are responsible for the operation of the energy pipeline network. A detailed account of each company's operations is outside the scope of this paper.

Bredell (2004:12) raises pertinent questions in respect of South African energy pipelines: to what extent the South African energy pipeline operators will be able first, to identify risks associated with the energy pipelines and, secondly, to manage risks such as pipeline pilferage, third party damage, leaks and corrosion. According to one senior interviewee of a pipeline company, pipeline risks in South Africa are very remote and the industry by and large has had a good safety record. While this may be true, the question still remains: What if it does happen? Interestingly, a few months after conducting the interview, a huge gas pipeline explosion occurred on 1 September 2010 in Johannesburg. It is instructive to mention that there are other pipeline leakages, albeit minor, that have occurred in South Africa in the past. According to a press release (4 October 2004, groundwork.org.za) the following are some of the examples cited:

- In June 2001, an underground fuel pipeline belonging to a joint venture between Shell Refining SA and BP Southern Africa (SAPREF) leaked leading to the discharge of more than a million litres of petrol into the south Durban area and the evacuation of people from their homes.

- On July 2001, a second leak was discovered and residents demanded that the pipeline be inspected immediately. 
- On 27 September 2001, a Shell/BP refinery third pipe leak was reported.

- On 2 April 2002 a hole was discovered on a SAPREF pipeline but it was claimed that no product was lost.

Thus, pipeline operators in South Africa need to acknowledge that there is always a possibility of risk occurrence that needs to be identified, assessed and managed. As Slay \& Koronios (2006:32) quite rightly pointed out, the concept of risk is broader and refers to an ordinary happening in which is hidden a small probability that can preclude a business from accomplishing its goals.

Consensus from the industry is that legislation in South Africa does not provide a clear legal framework with regard to quantified risk criteria in comparison with European Union and North America legislation. When risk criteria are applied, various alternatives exist which will be able to assist the pipeline risk assessors in formulating an informed opinion.

\section{Views and perceptions of industry}

In order to ascertain the appreciation of risks associated with pipelines, data was collected from companies that operate energy pipelines using a structured questionnaire. From the three major companies that operate energy pipelines in South Africa, two of the companies (hereinafter referred to as $A$ and $B$ ) were able to provide detailed information while the third, Company $\mathrm{C}$, was reticent in providing information. The information sought revolved around four questions which are highlighted below. Responses to these four questions would reveal whether the companies are aware of risks or not.

1. What risk factors are the energy pipeline supply chains mostly exposed to?

2. Which risk assessment model/process does the company use for their energy supply chains?

3. What type of pipeline inspection and protection measures does the company use for their energy pipeline supply chains?

4. What is the frequency of pipeline inspection?

In respect of risk factors that energy supply chains are mostly exposed to, the factors that the two companies cited were categorised into six areas. Table 2 shows the perceived level of risk exposure in respect of six factors that are deemed likely to occur in energy pipeline supply chains. 
Table 2: Perceived risks by pipeline operators

Source: Authors' survey

\begin{tabular}{|l|c|c|c|}
\hline \multirow{2}{*}{ Factor } & \multicolumn{3}{|c|}{ Rating in order of importance (\%) } \\
\cline { 2 - 4 } & Company A & Company B & Company A and B \\
\hline Environmental factors & $8 \%$ & $6 \%$ & $7 \%$ \\
\hline Pipe leaks & $9 \%$ & $19 \%$ & $14 \%$ \\
\hline Pipe erosion & $16 \%$ & $26 \%$ & $21 \%$ \\
\hline Pipe design & $17 \%$ & $9 \%$ & $12 \%$ \\
\hline Pipe sabotage & $1 \%$ & $2 \%$ & $2 \%$ \\
\hline Third-party damage & $49 \%$ & $38 \%$ & $44 \%$ \\
\hline
\end{tabular}

From the above figures, there is consistency with regard to the factors that energy pipeline companies are exposed to in South Africa. Companies perceive third-party damage (overall $44 \%)$ as posing the highest exposure to risk. Third-party damage entails accidental damage that can be caused to the pipeline. The Egoli gas pipeline explosion cited earlier is an example of third-party damage that was caused by workers who unintentionally struck the pipeline with an excavator when carrying out routine maintenance. The second highest perceived factor to risk exposure is pipe erosion. Pipe erosion is of concern to the companies as some of these pipelines were installed several decades ago and there is therefore a realisation that they are susceptible to damage. The least perceived exposure is sabotage (overall 2\%). Interestingly, sabotage features highly in other parts of the world as evidenced by oil pipeline disruptions cited earlier that occurred within the last decade. Environmental risks are perceived as low, whereas in the developed world such issues would feature prominently (www.oecd.org/dataoecd/15/16/37719119.pdf).

The second question pertains to the types of risk assessment models that the companies use for their energy supply chains. This is an important area of risk assessment as no one can argue the occurrence of an event with certainty especially with pipeline supply chains. There are a number of risk assessment models, which include, inter alia, the Matrix model, Probabilistic model, Index model, Phast system and ATMOS leak detection system.

Company $A$ uses the Phast Risk assessment model which is ideal for monitoring high pressure gas pipes. Phast Risk is a comprehensive software quantitative tool for assessing flammable, explosive and toxic impact and it is designed to analyse complex consequences from accident scenarios (www.dnv.com/services/software-/products/-safeti/.../phastrisk.asp).

According to a senior official of Company A, this control system ensures safe and effective gas flow, protecting humans, animals and property from fatal and destructive gas accidents. The system is designed in accordance with company requirements and it is continuously updated to ensure accuracy of information. The benefits that accrue to Company A from using the system are: 
- facilitation of cost reductions in terms of losses and insurance

- risk ranking and hazard zone identification for guidance concerning possible mitigation measures, including operating, emergency response or land use planning

- provision of traceability and consistency for energy pipeline calculations

- provision of gas flow reports with user-defined acceptance criteria

- incorporation of the consequence modelling of the Phast process hazard analysis.

Company B uses the Probabilistic model and ATMOS leak detection system. The former model is the most challenging and complicated risk assessment methodology. Probabilistic risk assessment is a highly mathematical and statistical tool (therefore data intensive) that is dependent on historic data. It is an advanced tool that requires more trained operators to achieve a thorough risk assessment.

The ATMOS leak detection system, which is also used by Company $B$, is extensively used worldwide. According to a senior Company B official, the system monitors the pipeline energy supply chain and the information regarding flow rate, pipeline pressure, temperature and density is instantly made available. The benefits for Company B of using this system are:

- collection of flow, pressure, temperature and valve data at 30-second intervals

- validation of the above data so that faulty instruments are diagnosed and incorrect data rejected

- detection of leaks under different operational conditions

- estimation of leak size and location

- record of historical data and events

The third question in ascertaining risk awareness sought responses on types of inspection and frequency measures used on pipeline supply chain risks. Company A employs measures such as foot patrols, computer monitoring and inspection with an aircraft. Company B employs CCTV for pump stations and terminals, inspection by helicopter, computer monitoring and vehicle as well as foot patrols. The fact that a variety of inspection and protection measures are employed is indicative of the awareness of potential risks that are likely to occur to energy supply chains.

Both companies conduct regular protection measures: on a daily basis, once a month, six times a year and when an incident takes place. The intensity of inspections increases with longer time intervals. Notwithstanding the argument by Valsamakis, Vivian \& Du Doit (2005:7) that risk management surrounding the business energy pipelines environment in South Africa is still at an embryonic stage, the industry is certainly aware of the risks involved in pipeline operations. 


\section{Public perceptions and awareness}

\section{Study setting}

A household survey was conducted in the Parktown residential area of Johannesburg as it has a network of gas pipelines. The objective of the survey was to ascertain the awareness of the general public to energy pipeline risks. Figure 1 depicts the macro and micro location of the study area.

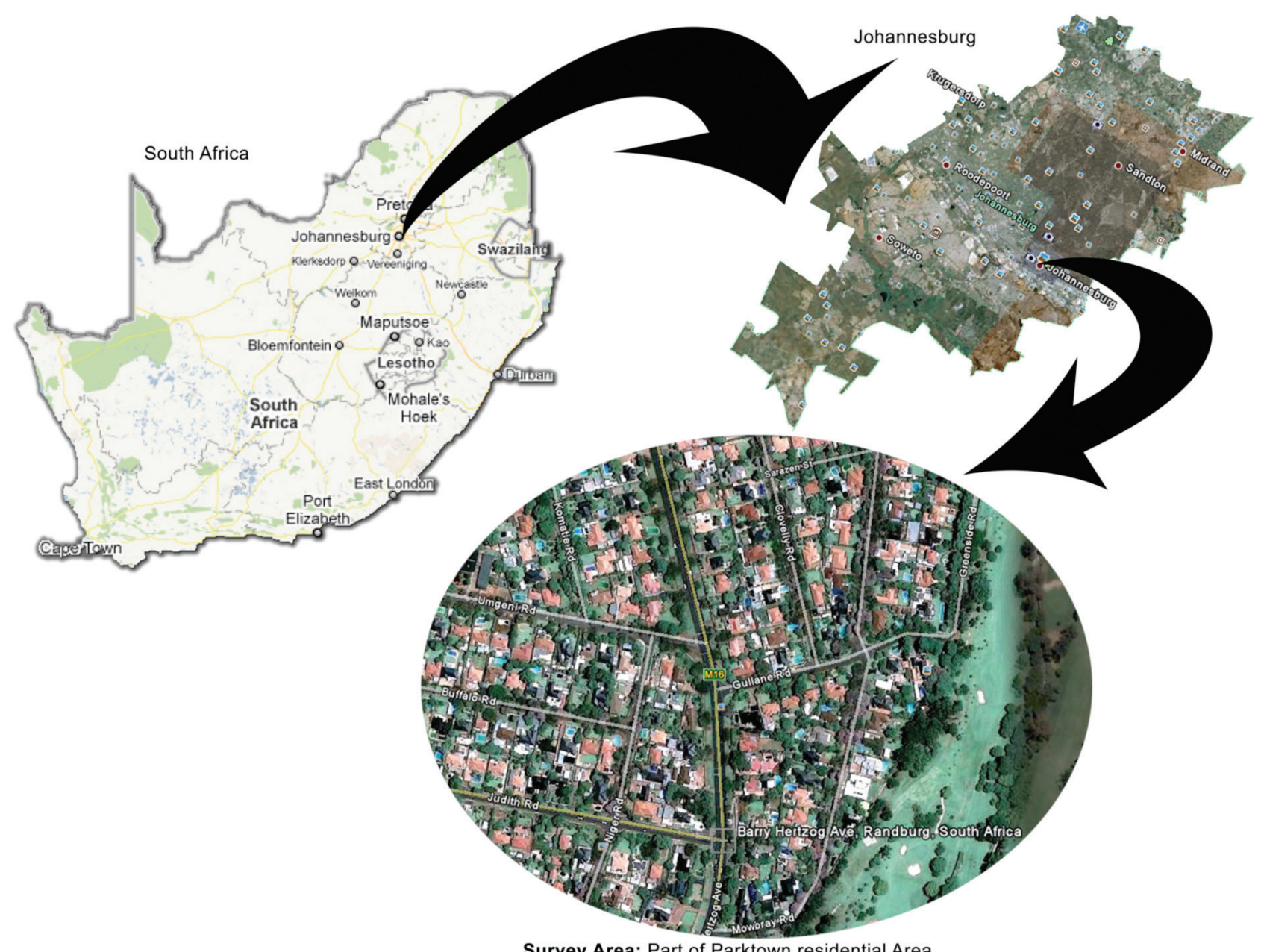

Survey Area: Part of Parktown residential Area

Figure 1: Macro and micro location of study area

Source: Google Maps

This area was chosen because of its proximity to the researchers' base as well as its having a network of gas pipelines. The questions sought to ascertain, inter alia, whether the household was connected to the gas supply, knowledge of the location of gas pipelines in the vicinity, awareness of risks associated with gas pipelines and remedial measures therefor. The questionnaire was administered to the most senior member of the household (male or female) available at the time of conducting the interview. 
A total of 125 households were randomly interviewed. Of these, 55 (44\%) were connected to gas and 70 (56\%) not connected. From the households that were connected to the gas supply, the average number of years that they had been using gas was 11.5 years with a minimum of 0.5 years and a maximum of about 50 years.

Fifty-one per cent (51\%) of the interviewees were female and $49 \%$ were male. The gender distinction was made in order to also ascertain (out of academic interest) whether there are differences (statistically) in risk awareness between male and female.

\section{Perceptions and awareness}

An analysis of data showed that $73 \%$ of households not connected and $53 \%$ of households connected to gas supply were not aware of the actual location of the gas pipeline in their neighbourhood. In respect of risk awareness, $44 \%$ of households not connected were aware of potential risks related to energy pipelines while $64 \%$ of those connected were aware of such risks. The risks cited by households who were connected and not connected to gas supply are shown in Table 3.

Table 3: Perceived risks by the public

Source: Authors' survey

\begin{tabular}{|l|r|l|r|}
\hline \multicolumn{2}{|c|}{ Households not connected } & \multicolumn{2}{c|}{ Households connected } \\
\hline Risk factor & Percentage citing & Risk factor & Percentage citing \\
\hline Don't know & 46 & Don't know & 36 \\
\hline Leakages & 24 & Leakages & 39 \\
\hline Explosions & 4 & Explosions & 19 \\
\hline Fire & 9 & Fire & 3 \\
\hline Damage & 9 & Installation & 3 \\
\hline None & 8 & Total & 100 \\
\hline Total & 100 & & \\
\hline
\end{tabular}

From Table 3, the proportion of households who are completely unaware of the risks of gas pipelines is high. In respect of households not connected to gas supply, $46 \%$ were completely unaware of risks associated with gas pipelines. In addition, $8 \%$ of these households thought there were no risks at all associated with gas pipelines. The risks cited were leakages (24\%), explosions (4\%), and fire and damage with $9 \%$ each. The interviewees failed to explain how 'damage' can be a risk factor. Interestingly, the factor was only mentioned by those households not connected to the gas supply.

Households connected with gas had a relatively higher level of awareness in comparison with those not connected. Thirty-six per cent (36\%) were completely unaware of risks associated with gas pipelines. Risks cited by households pertained to leakages (39\%), explosions (19\%) 
and fire 3\%. Three per cent of the households identified installation as a risk which was explained as one of the potential problems that might arise when installing and maintaining gas pipes. Such problems may include the risks of damage and/or explosion.

The citing of leakage as the most common risk associated with energy pipelines by both households who are connected and not connected to gas supply is not surprising. Most residents were aware of a leakage that had been occurring intermittently for over 18 months in the neighbourhood and referred to it often. As one male respondent remarked: 'There is a hole which has been dug at the golf course where gas leakage has been going on for a long time and it seems the responsible people can't fix it. It is a very old system. At times it gets to the point where you can smell it.'

Residents connected to gas were asked to suggest further precautionary measures that need to be taken to minimise potential risks of energy pipelines. The majority (67\%) failed to identify measures that would minimise the occurrence of risks. Twenty-nine per cent (29\%) and $4 \%$ respectively cited regular maintenance and adherence to instructions as precautionary measures that can be applied.

The above results show a generally low level of public awareness of risks associated with energy pipelines with a relatively higher level of awareness by those connected to gas supply in comparison to those not connected. Two questions can be raised:

1. Is there an association in knowledge of the location of the pipeline between those connected with those not connected?

2. Is there an association in knowledge of actual risks between those not connected and those connected?

The two questions are critical in ascertaining whether communities are aware of the risks involved with energy pipelines. If someone is not even aware of the location of an energy pipeline in the vicinity of their home, it is most likely that the person is also not aware of the risks associated therewith. It was therefore necessary to carry out tests of significance (Chisquared tests) in order to make meaningful interpretations of the above questions. Tests of significance conducted revealed the following:

- There is no association in knowledge of the location of the pipeline between people connected and those not connected to the gas supply as the p-value $(0.607)$ is greater than the significance level (0.05); $\mathrm{p}(0.607)>0.05$.

- There is a slight association in level of awareness of gas pipeline risks between those connected and those not connected as the p-value $(0.083)$ is marginally greater than the significance level (0.05); p(0.083>0.05). 
It is evident that knowledge of the actual location of the pipeline is not dependent on whether or not households are connected to gas. A significant number of households connected to gas pipelines are not aware of the pipeline's location. Even though the results reveal the lack of association of awareness of pipeline risks between households connected and those not connected, the marginal differences between the p-values is indicative of a slight association. One would expect a greater association as those connected should be more knowledgeable about the risks of energy pipelines. On the whole, public awareness of risks associated with energy pipelines is very low.

The analysis was further extended to ascertain whether gender had an influence on awareness. The test of significance results revealed that there was no association between gender and risk awareness as shown below.

- There is no association between knowledge of the location of the pipeline and the gender of the participant interviewed as the $p$-value $(0.566)$ is greater than the significance level (0.05); $p(0.556)>0.05$.

- There is no significant difference between the gender of the participants interviewed and awareness of risks for those connected to the gas supply as the p-value (0.229) is greater than the significance level (0.05); $p(0.229>0.05)$.

\section{DISCUSSION}

\section{Towards a risk awareness and management process for the energy pipeline supply chain industry}

Muhlbauer (2004) identified a number of risk management processes that are ideal in energy pipeline supply chains. Such a process would further enhance risk awareness, and is ideal for South African organisations that operate pipelines. The steps are depicted in Figure 2 (developed by the authors).

The first step involves the determination of a business risk model to use for energy pipelines. As already discussed, there are different assessment models that are available for the risk evaluation process. Companies in South Africa can modify an existing model to tailor it specifically for an individual organisation's business environment. 

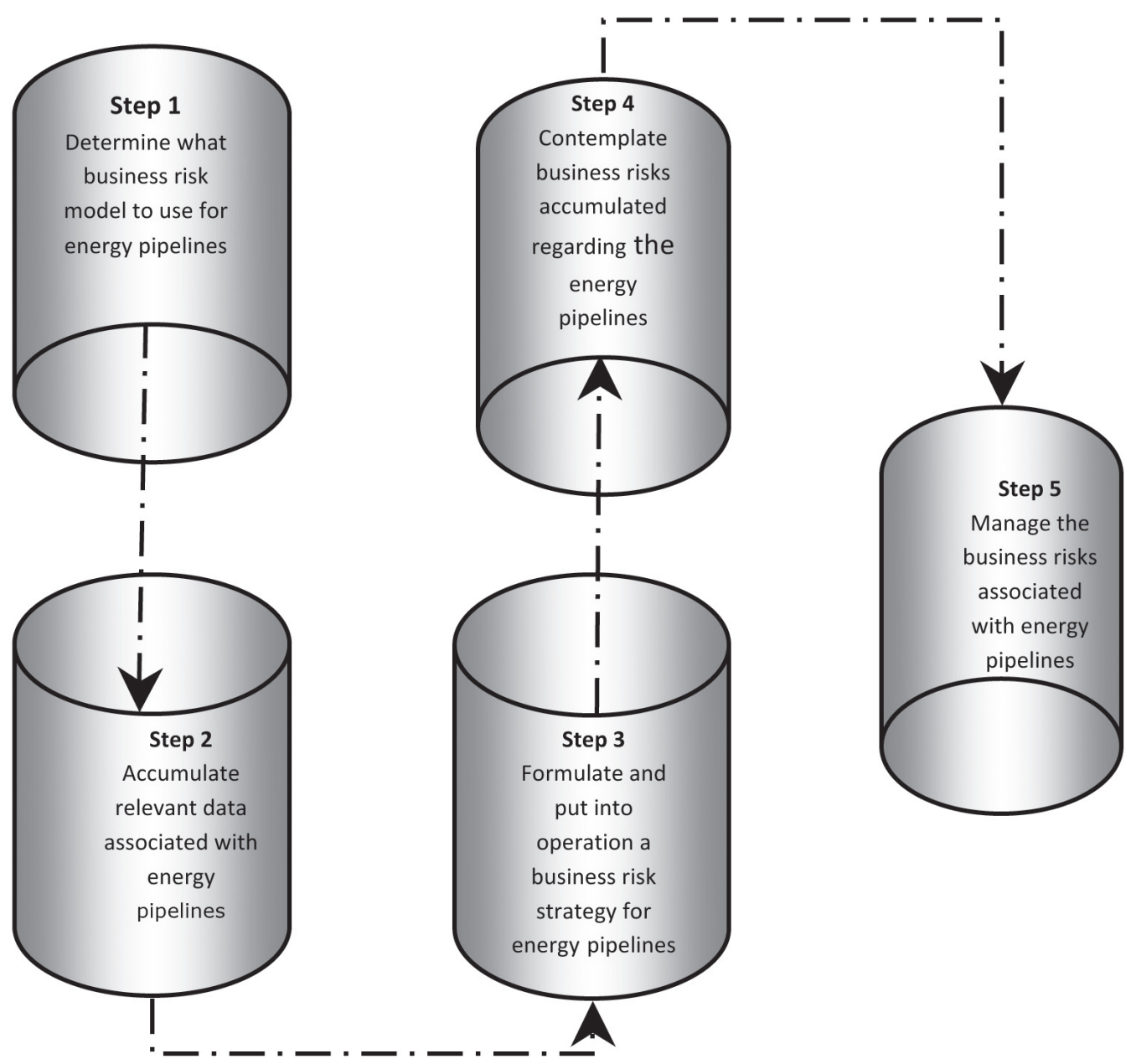

Figure 2: Business risk management process

Source: Developed by authors

The second step requires the collection of relevant data. According to Ritter et al. (2007:83) the more well-founded information you have at your disposal, the more certain you can be of an outcome. The data can come from a variety of sources including workshops, brainstorming sessions, lessons from history and benchmarking with other organisations, among others. This is an important step as it can incorporate public awareness as well.

The formulation and putting into operation a business risk strategy is the third step of the risk management process. While pipelines are considered to be the safest mode of transport, it is imperative that the operational side be managed in a continuous manner by crafting a business risk strategy.

The fourth step entails the consideration of all business risks accumulated in regard to energy pipelines. Vertzberger (1998:23) suggests the use of statistics from previous years as a guideline for the prediction of forthcoming risks associated with pipelines. Another way recommended by Ritter et al. (2007:96) is to categorise the possible risks into four groups, namely catastrophic, critical, marginal and negligible. 
The final step is the actual execution of the business risk management process which involves bringing together all the concepts and ideas identified and highlighted in the four steps discussed earlier. The objective for managing business risks associated with energy pipelines according to Young (2006:34) is to make certain that energy pipeline risk methods and processes are operating effectively and resourcefully. Thus, it becomes imperative that the process adopted should continuously monitor the risks identified and related to the business environment of energy pipelines. Finally, as the energy business environment changes from time to time, risk management methods have to be reviewed as well.

\section{Corporate versus public awareness}

The corporate energy sector in South Africa is clearly aware of possible risks to energy pipeline supply chains. Although the argument that the South African pipeline energy sector hitherto has had a relatively safe record, the corporate sector has taken measures to minimise such risks. The extent to which such measures are being implemented may be affected by the preconceived view of 'a past safe record' that the pipeline supply chain operators quote. However, the pipeline disruptions which have occurred, although minor, should not allow the industry to become complacent as a major disaster can happen at any time.

In contrast, the general public's awareness of risks associated with energy pipeline supply chains is very low. This is also evidenced by questions raised by some members of the public on the relevance and importance of their being aware of risks associated with energy pipelines. In the case of a major disaster, the public might not know how to react as they are in the first instance not even aware of pending risks. This was evident in the 2010 San Bruno pipeline explosion (referred to earlier) when some of the people did not know how to react.

Corporate and public perceptions of risks associated with energy pipelines differ remarkably. For the corporate sector, third party damage poses the highest exposure to risk while leakages are perceived as the greatest risk by the public. The corporate sector is aware of the environmental risk factor (albeit a low ranking) that may occur in energy pipeline operations whereas the public is totally oblivious to this factor. For the corporate sector, sabotage has a very low possibility of occurrence. The sabotage risk factor was not cited at all by members of the public, indicative of total ignorance of its likelihood.

The findings of this paper were initially presented at a conference where interesting reactions were noted. A fundamental question was raised on whether sellers of houses should not disclose information on the existence of pipelines in those environments where they exist. While such a suggestion might sound alarming, the bottom line is that energy supply chain companies need to be proactive and positively communicate information on possible risks to the public without raising anxieties. 


\section{CONCLUSION}

Pipeline risk management is increasingly becoming a major concern as disruptions can adversely impact the provision of energy products resulting in price escalation. Consequently, risks associated with energy pipeline supply chains are to be identified, managed and controlled if energy pipeline organisations are to operate effectively. Energy pipeline supply organisations in South Africa need to realise that supply chain risks are increasing as the business environment comes under pressure from global competitors. Even though the local industry is aware of supply chain risks, success in managing risks is hinged on implementation of a long-term risk management strategy which includes dissemination of relevant information to all stakeholders including the general public. The paucity of risk management literature in the pipeline sector in the country is evident and this is one limitation that needs to be addressed.

In view of the dearth of literature in this area of pipelines it is recommended that an examination be conducted with the view of embarking on an appropriate academic programme in conjunction with the South African energy pipeline supply chain organisations. Exposure to this field of study would greatly assist the energy pipeline supply chain industry to properly educate their company personnel regarding the various risks to which their operations are exposed. In addition, such a programme would enhance public awareness on the importance of pipeline transport.

The lack of awareness by members of the public warrants a need to raise an understanding on risks associated with energy pipelines. This can be achieved through workshops, seminars, dissemination of pamphlets and road shows. Notwithstanding a good safety record that the country has sustained without a major pipeline disaster, the question remains: What if it does happen? 


\section{REFERENCES}

Anchorage/New York. 2011. 10 January. Alaska pipeline restart unknown; oil up, BP dips. Available: www.reuters.com/.../2011/.../us-oil-pipeline-alaska-idUSTRE7080H820110110.

The Associated Press. 2010. State Senator says 6 killed in California explosion. 10 September 2010. www.kolotv.com/californianews/headlines/102590744.html.

Bardi, E.J., Coyle, J.J. \& Novack, R.A. 2006. Management of Transportation. Thompson Corporation, Mason, Ohio.

Borge, D. 2001. The Book of Risk. John Wiley and Sons, New York.

Bredell, R.D. 2004. Supply chain risk management: A logistics perspective. Unpublished DCom Thesis, Rand Afrikaans University.

Elliott, L. 2004. Iraq sabotage fear deepens oil crisis. In The Guardian, 10 August 2004, Available: www.guardian.co.uk/business/2003/aug/18/iraq.oilandpetrol.

Gifford, G. 2010. Huge gas explosion lifts giant digger. In The Star, 1 September 2010.

Houreld, K. 2006. Nigeria pipeline explosion kills 260. Associated Press, 27 December 2006.

Interstate Natural Gas Association of America (INGAA). 2011. Natural Gas Transmission Pipeline Public Awareness and Engagement.

Janis, I. \& Mann, L. 1977. Decision Making: A Psychological Analysis of Conflict, Choice and Commitment. New York, Free Press.

Liu, H. 2003. Pipeline Engineering. Lewis Publishers, Corporate Boulevard, Boca Ranton, Florida.

Luft, G. \& Korin, A. 2004. Terrorism goes to the sea. New York Times (7 December 2004). Available: www.nytimes.com.

Lyons, D. 2002. Western European cross-country oil pipelines 30-year performance statistics. Consultancy report prepared on behalf of CONCAWE oil pipelines Management Group (OPMG). 
Mileti, D. 1993. Communicating public earthquake risk information. In: Prediction and Perception of Natural Hazards. J. Nemec, J. Nigg, and F. Siccardi (eds). Boston: Kluwer Academic Publishers.

Muhlbauer, K.W. 2004. Pipeline Risk Management Manual: Ideas, Techniques and Resources. Third Edition, Gulf Publishing Company.

Pickford, J. 2001. Mastering Risk. Volume 1 Concepts. Pearson Education Limited, London.

Pienaar, W.J. 2010. Logistics aspects of petroleum pipeline operations. Journal of Transport and Supply Chain Management. Volume 4, Issue 1.

Press release. 2004. 4 October. Information on south Durban's Leaking Fuel Pipelines Withheld. www.groundwork.org.za/Press\%20Releases/04oct04stthDbn.asp.

Pritchard, P. 2001. Environmental Risk Management. Eathscan Publications Ltd, London.

Ritter L., Barrett, J.M. \& Wilson R. 2007. Securing global transportation networks: A total security management approach. The GcGraw-Hill Companies, New York.

Rosa, E.A. 2003. The logical structure of the social amplification of risk framework (SARF): Metatheoretical foundations and policy implications. In N. Pidgeon, R.E. Kasperson \& P. Slovic (eds.): The Social Amplification of Risk. (pp. 47-79). Cambridge: Cambridge University Press.

Salopek, P. 2003. Iraq's oil economy hit by another pipeline explosion. Chicago Tribune, 25 June 2003.

—. 2003. Saboteurs hit another Iraq pipeline. In the tribute, 26 June 2003, Available: articles.chicagotribune.com/.

Slay, J \& Koronios, A. 2006. Information Technology Security and Risk Management. John Wiley \& Sons, Australia.

Tarbell, I.M. 1904. The history of the Standard Oil Company. Available: The History of Pipelines, www.pipeline101.com/history/index.html.

Trench C.J. 2001. How pipelines make the oil market work - their networks, operation and regulation. A memorandum prepared for the Association of Oil Pipe Lines and the American Petroleum Institute's Pipeline Committee Allegro Energy Group. www.pipeline101.com/ reports/Notes.pdf. 
Valsamakis, A.J., Vivian, R.W., Du Doit, G.S. 2005. Risk Management: Managing Enterprise Risk. Third Edition, Heineman Publishers (Pty) Ltd.

Vertzberger, Y.Y.I. 1998. Risk taking and decision making: Foreign military intervention decisions. Stanford University Press, California.

The World Factbook. 2008. Field Listing - Pipelines www.faqs.org/docs/factbook/ fields/2117.html.

Young, J. 2006. Operational risk management: The practical application of a quantitative approach. Van Schaik Publishers, Pretoria.

www.enotes.com/topic/List_of_pipeline_accidents.

www.oecd.org/dataoecd/15/16/37719119.pdf. Economic aspects of environmental compliance assurance. Proceedings from the OECD Global Forum on Sustainable Development. 2-3 December 2004, OECD Headquarters, Paris, France.

www.dnv.com/services/software/products/safeti/.../phastrisk.asp, Phast Risk - onshore Quantitative Risk Assessments.

\section{Acknowledgements}

This paper partly culminates from a Magister Commercii (M Com) dissertation by Hugo van den Berg (Promotor: Dr B Kujawa; Co-Promotor, Dr V Mostert). The authors wish to thank all the people who were interviewed: pipeline operators, consultants, Government departments and household members in the Parktown residential area. Special thanks to Mrs Lyness Matizirofa for her assistance in the statistical analysis. 